\title{
Clustering of Small Businesses - New Opportunities to Improve the Competitiveness of Latvia
}

\author{
Svetlana Stradinya ${ }^{1, *}$, L. Beinerte ${ }^{2}$ \\ ${ }^{1}$ Baltic International Academy, Latvia \\ ${ }^{2}$ Baltic International Academy, Faculty of Regional Economy, Latvia
}

Copyright $\bigcirc 2016$ by authors, all rights reserved. Authors agree that this article remains permanently open access under the terms of the Creative Commons Attribution License 4.0 International License

\begin{abstract}
The article presents the study of life span of small and medium business in Latvia. Investments that come from EU funds show little help for little and microbusinesses. Private business can't withstand the market forces, changing economic and political realities. To survive, he must embark on way of clustering, which is adaptable and resistant to change. The process of clustering is shown of small and medium-sized businesses, the existing problems and the need of support from the state.
\end{abstract}

Keywords Small and Medium Businesses, Clustering Process, Innovation Clusters, Public Policy

\section{Introduction}

In many countries, small businesses play an important economic and social role in the development of the economy as a whole. The level of development of many small businesses depends on variables such as the level of competition, the introduction of new technologies, production efficiency and so on. Finally, the development of small business - a growing number of people, who independently provide a decent standard of living for themselves and their families.

Small business development creates the prerequisites for accelerated economic growth, contributes to the diversification and saturation of local markets, a decrease in unemployment. Small business creates favorable conditions for the active process of economic recovery as developing a competitive environment, are additional sectors and more. In addition, small business development leads to the saturation of the market in goods and services, to increase export capacity, better utilization of local raw materials.

If until recently, the economies of many countries developed mainly through the mechanism of competition, today main route to the harmonization becomes cooperation, community, in its active cluster forms. This circumstance forces to seek new forms of conservation of small businesses and to translate it from the competition and to the community of cooperation. This form can now be called its clustering. This cluster approach can be an effective tool to stimulate economic development of small business enterprises. For small businesses cluster - this is an opportunity to secure a competitive position in the future that is to create long-term strategy of enterprise development.

The cluster, as a specific configuration of the activity of enterprises, can only grow, it has not an external (exogenous), but internal - (endogenous) nature. It can't be established by decision from the top. However, the state should create conditions for the cultivation of clusters of small and medium-sized companies that enhance the competitiveness of the national economy as a whole. This aspect is very important for Latvia, because the creation of favorable conditions can give a strong impetus to this process.

At the present stage it becomes not only economic but also a political task. Indeed, the efforts made by the governments of different countries, have helped to improve and transform small and medium enterprises so that he can be competitive in a rapidly changing global economy.

Significant role in these matters have EU funds. Latvia over a ten-year stay in the EU has received investments from various funds, but they have poorly promoted the development of the clustering of small and medium-sized businesses. Considering the demand of the time, there is a need to support small businesses through the Latvian state by conducting and supporting cluster policy.

Matters considered in this article make not the whole list of problems that impede the process of clustering of small and medium-sized businesses in Latvia. But even they are a brake on the development of the economy and increase of its competitiveness.

The purpose of the article - to identify the main reasons hindering the process of clustering of small businesses in Latvia, the necessity of its support from the government and the recommendations to address these problems. For the purposes of the study, the authors used the methods of observation, comparison, facts gathering, conversations and interviews, analysis and synthesis. 


\section{Brief Literature Review}

One of the first studies of clusters has been presented in the work of Michael Porter's «The Competitive Advantage of Nations». In this study, based on the analysis of economic processes, a significant number of countries, Porter suggested that they get a significant competitive and economic advantage due to the concentration of businesses in the same or related industries [1].

In subsequent studies, says Porter, these competitive advantages are derived from the territorial and sectoral linkages enterprises within these clusters. These companies greatly simplify the dissemination of innovations have access to qualified personnel and many others. It can be argued that clusters promote the complementarity of their members, creating competitive advantages of the cluster as a whole and explaining their business activity [2]. The idea of Porter became one of the most significant manifestations of the approach due to the localization of the economy, and in fact, may be the most significant. At the same time, Porter suggests the idea of clustering, not only as an analytical concept, but also as an instrument of economic policy [3].

In Maskell study argues that the reason for the formation of clusters caused by the co-location of firms in related industries. This extends the capability to create new competencies through innovative changes and deepening division of labor. Thus, there is a cluster of expanding the knowledge base and innovations which define its dimensions [4].

In recent years, sharply increased interest in clusters consists mainly of small firms. On the one hand, matured prerequisites for the formation of close technological ties between small producers. On the other hand, the opportunity to implement national advantages by forming clusters of small businesses in unrelated sectors of the economy.

In the scientific literature there is a view that the representatives of small and medium businesses - the segment, which is characteristic of the greatest interest, and even the initiative in the creation of clusters. In world practice, the developed countries stimulating innovative development of small business stands out as an independent direction of government regulation [5].

As noted Ketels, interest in clusters has increased because they are a practical lever of influence, not just a way of describing economic reality. The cluster approach to solving the problems of competitiveness is based on the fact that the disparate acting alone and small and medium-sized producers are not able to withstand market forces cannot provide a high rate of growth of labor productivity and reduce costs, not to mention innovation [6].

In modern conditions the cluster concept is becoming more and more associated with the so-called knowledge economy, innovation, information economy. Thus, the scientific and practical interest present the works of foreign experts in the field of theory and practice of formation of national innovation systems and learning economy Lundvall B., Johnson B. [7].
In this issue we should agree with Ketels, who believes the best policy in support of clusters - a policy of "cluster activation" [8]. It means that the state's role should be limited to the removal of barriers hindering the formation of clusters, above all, improving the business environment habitat, creating infrastructure in order to enable the cluster to develop independently

As Enright M. says the initiator of the cluster policy can be not only the central government, which has carried out cluster policy 'from above', but also regional or local business associations that offer implementation of incentive programs of development of clusters "from below". These programs are called "cluster initiative» (cluster initiative) [9]. The findings of this analysis will guide decision-makers of the North Sea Region and the North West Europe programmes when setting rules and procedures for the next period 2014-2020.

In general, the above-mentioned authors have one thing in common, that the presence of clusters helps national industry to develop and maintain its competitive advantage, not giving them even technically developed countries. And in those countries dominated mostly small businesses, its clustering issues should be raised to the level of state regulation.

\section{The Main Results of the Research}

Small and medium enterprises in Latvia - it is $95 \%$ of all enterprises, which employ $70 \%$ of the Latvian labor force and produce $65 \%$ of gross domestic product. In Latvia, about 36 thousand microenterprises [10].

According to the Register of Enterprises, at the beginning of 2015, Latvia has been active 129.3 thousand. Commercial entities with different status, traffic and business profile. Of these, almost $90 \%$, have the status of small family firms micro and small enterprises with an annual turnover of less than 200 thousand euros [11].

Within the framework of the industrial policy of Latvia a number of programs being implemented now, aimed at improving the competitiveness of the Latvian economy. Helps European program to support the economy, aimed at reducing the level of development of the EU countries. Latvia continues to receive solid enough grants from the central EU funds. This support allows you to almost completely cover the costs of the organization of enterprises and stimulate their development.

Investment and Development Agency of Latvia continues to provide support for businessmen in the framework of the EU Structural Funds (development of new products and technologies and their support). However, this support is, as a rule, those organizations that have crossed line of small and medium-sized enterprises [12]. This is indicated by Figure 1. 


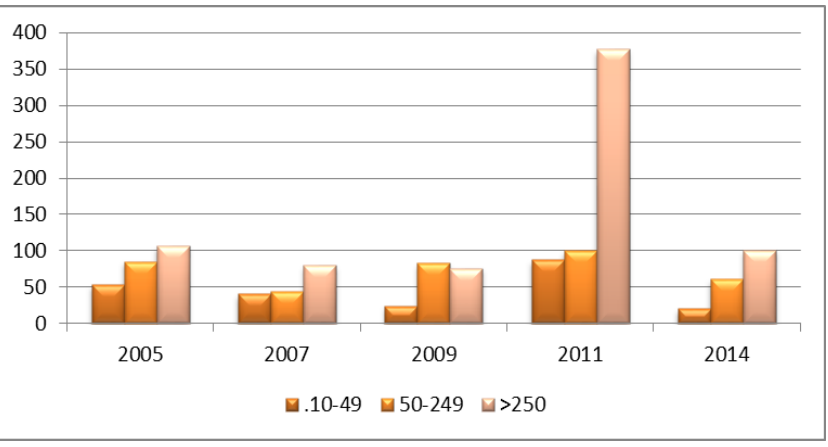

Figure 1. Total spending on innovation largest enterprises in Latvia ( $\mathrm{mln}$. Euro) (Compiled by the author)

As can be seen, in spending on innovation are leading enterprises with employment of more than 250 people. However, small and medium business the allocated funds are negligible. Therefore, the competitiveness of small and medium-sized enterprises remains a matter of concern. In Latvia, the use of the economic potential of small and medium-sized business is not a priority of the state policy, as evidenced by the imperfection of the system of state support.

In order to ensure further development of the country, simple infusion of capital in the economy will not be enough. The development and use of human capital is necessary. Solving the problem of increasing the share of small and medium-sized businesses in the structure of the economy, it is necessary to pay attention to human potential, capable of practical implementation of business ideas.

Small and medium business provides almost two-thirds of GDP and most of the jobs in the country. It is a small business because of its flexibility, agility, adaptability to environmental conditions ensures the stability of the solution of problems of employment and social stability in the country. However, the competitiveness of small and medium-sized enterprises remains a matter of concern. Moreover, he farmed out to other more developed countries.

The main sources of foreign direct investment in Latvia the neighboring countries of the Baltic Sea region investment from Sweden, Germany, Denmark, Estonia and the Netherlands account for $42.4 \%$ of the total, covering many areas of finance, telecommunications and trade to create a fully export-oriented production. Investors from the US, Cyprus and Russia are choosing Latvia as a market base in the Baltic region and as a favorable place for production. Since the beginning of the 1990s, Sweden in Latvia - the largest investor (over $20 \%$ of the total investment, while other countries invest no more than 10\%) [10]. These investments come mainly in the banking sector, forestry, heavy industry. Swedes in Latvia held a large part of the entire communications: fixed, mobile, Internet and cable TV.

In Latvia, due to the weak state support Small and medium business is bought by the Swedes, Norwegians, Germans, Danes. The apparent takeover of foreign investors over small and medium-sized businesses has a negative impact on economic development and standard of living. Thus, well-known in his time in Latvia brands - Laima Staburadze and in 2013 bought the Norwegian giant Orkla. Large woodworking enterprise in terms of turnover (186 million. Euros) in 2005 purchased the Austrian-Swiss group Kronospan. The company Valmieras stikla šķiedra (VSS) for the production of fiberglass products bought German multimillionaire Jürgen Preiss-Daimler. Icelandic businessman, Jon Gudmundsson 2004 controls in Latvia several major industrial assets. For example, he owns the country's largest sawmill Vika Wood and of products of wood BYKO-LAT.

In order to survive and maintain its market for Latvian small businesses is vital to the formation of clusters. There is a bright example in the veterinary sector, where the company leader having about $45 \%$ of the local market, has initiated the creation of the cluster. This helped to ensure local companies hold market, quite competitive with Scandinavian clusters, leading an aggressive policy of capturing the local market. At the same time, the company successfully establishes horizontal links with six leading veterinary clinics, training center in the Latvian agricultural university, and government agencies. Companies optimize reallocation cluster patients based on the specialization of each.

Movement in this direction is gaining momentum. Companies unify services for survey of patients, create friendly software to facilitate the exchange of information and the results of the survey are actively involved in the training of personnel. The main objective of the cluster - a networking mutual communication and education cooperation between all cluster members. Additionally, the basic functions of the cluster - is to ensure mutual coordination of the participants in order to attract additional funding for other programs. These clusters are characterized by a special innovative environment, the development of horizontal ties and strengthen cooperation 'between firms that increase their competitiveness and survival.

New relationships within the cluster to stimulate innovation, promote the development of advanced technologies and the improvement of all stages of joint economic activities. There is a free exchange of information and the rapid spread of innovations through the channels of suppliers or customers. Relationships lead to the development of new routes within the cluster in gaining competitive advantage and generate a new kind of interaction, allowing them to maintain the status of a legal entity and to cooperate with other enterprises, forming a cluster. It was with the creation of the cluster creates synergy, through the development of strategic priority, resource allocation and structuring, creation of a training center and retraining, implementation, allowing to develop, grow and improve competitiveness.

Small and medium-sized enterprises in the cluster in the course of the interaction and convergence of interests gradually overcome fragmentation, inertia and isolation on domestic issues, which is conducive to the growth of their technological level and competitiveness. The development of clusters enables small businesses to find their consumers, to improve their competitiveness. We can say that for many countries, innovative cluster - this is a familiar industry (and not only) cooperation, which is based on modern principles 
of business development.

Effective functioning of small forms of production is determined by a number of advantages in comparison with the large-scale production: the proximity to the local markets and adaption to customer requests; production of small batches (which unprofitable for large firms); elimination of redundant control units, etc. Small production contributes to differentiation and individualization of demand in the field of industrial and personal consumption.

As an informal association (cluster is not a legal entity), it is intended to generate new forms of inter-firm cooperation, consciousness and thinking people. Within the space of cluster small business comes from the rivalry and confrontation to active cooperation, combining new forms of knowledge and risk-sharing with other partners in achieving their goals.

Cluster development can and should be a key element in building a new economy. International experience has shown that performed the majority of all innovations that contribute to scientific and technological progress and development of the "middle class" as a major factor of social and political stability of the society in the field of small business. Small businesses in Latvia do not have sufficient resources for research or qualified and creative personnel, who could implement innovative projects and develop new technologies.

Benefits for small businesses from the cluster development is largely dependent on industry characteristics, but generally they may consist in increasing the efficiency and reducing costs in the current activity, flexibility and innovation potential for creating new products, technologies and markets. We agree with the M. Porter, who argues that it is necessary to support the development of all without exception of clusters, because it is impossible to predict what the cluster will develop faster and some slower. Therefore, the Government's policy, under which assistance is provided only to those clusters that are currently high rates of development, is wrong [13].

The following example shows involvement of regional authorities in the formation of the cluster. Activities at Space Technology Cluster (STC) were launched in 2008 in accordance with the contract with the Investment and Development Agency of Latvia [14]. The main task of STC is to promote cooperation of space and high technology enterprises, research institutions, higher education institutions, and non-governmental organizations to facilitate their competitiveness and export ability, thus improving growth of Latvian economy.

The main objective of the Foundation VHTP is to provide all the necessary infrastructure and support services for the development of companies that are engaged in the field of high technologies and perform its activity in the city or region of Ventspils. Cluster coordinated by the Ministry of Education and Science, economics, defense, transport, cooperating with the European Space Agency (ESA), presents the national space strategy and provides assistance for research and scientific development of the industry. Participation in ESA is the connection with the two cost positions, in terms of public administration side, i.e. the annual State fee and the national administration and coordination costs.

The cluster consists of 10 key activities: space, security, transportation, medicine, food, agriculture, biotechnology, information and communication technologies, the environment and others. First, the cluster includes about 20 organizations, in 2010 there were 28 , and now there are about 44 participants, including some 20 businesses, 10 research institutions, five educational institutions, and non-governmental organizations.

Consider the performance of the cluster of space technologies (Figure2).

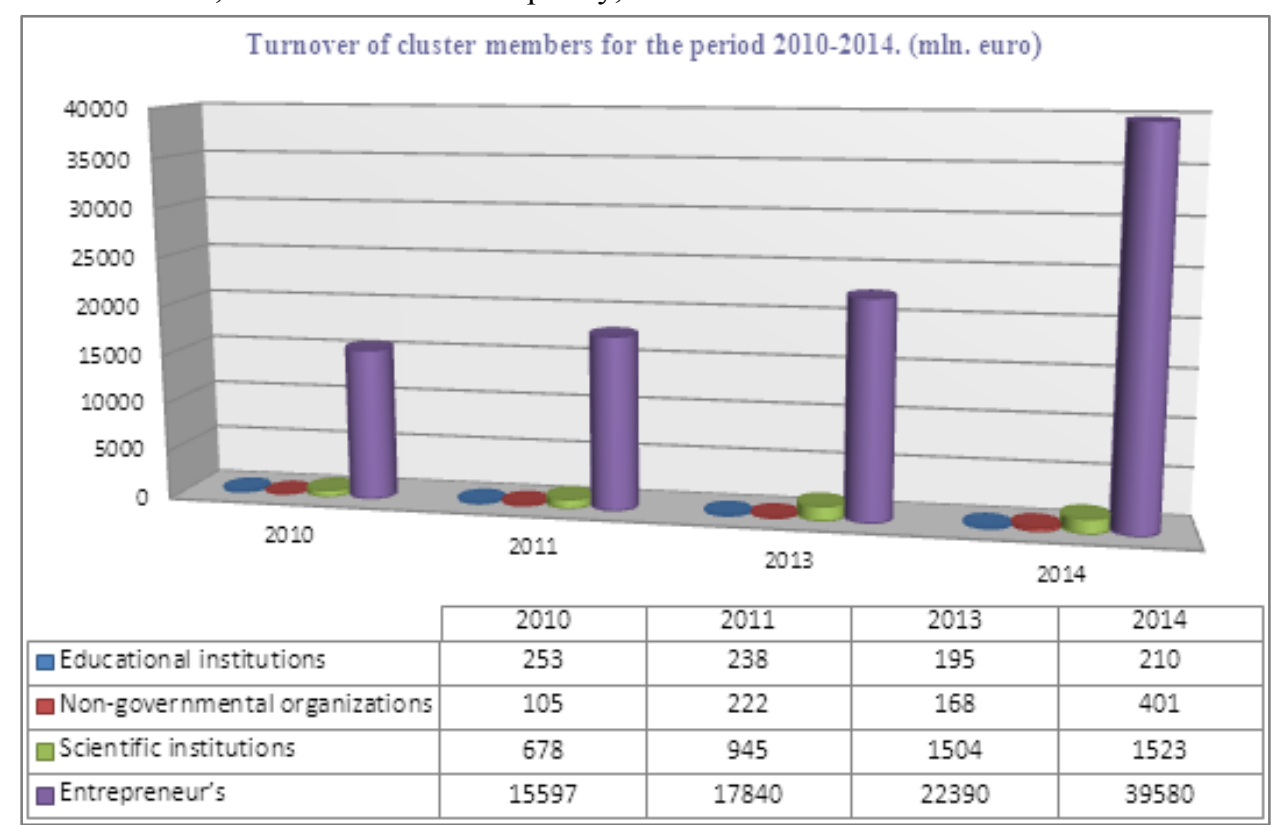

Figure 2. The total turnover of the participants of the cluster of space technologies and services for the 2010-2014 biennium /Turnover in the space sector/ (Compiled by the author) 


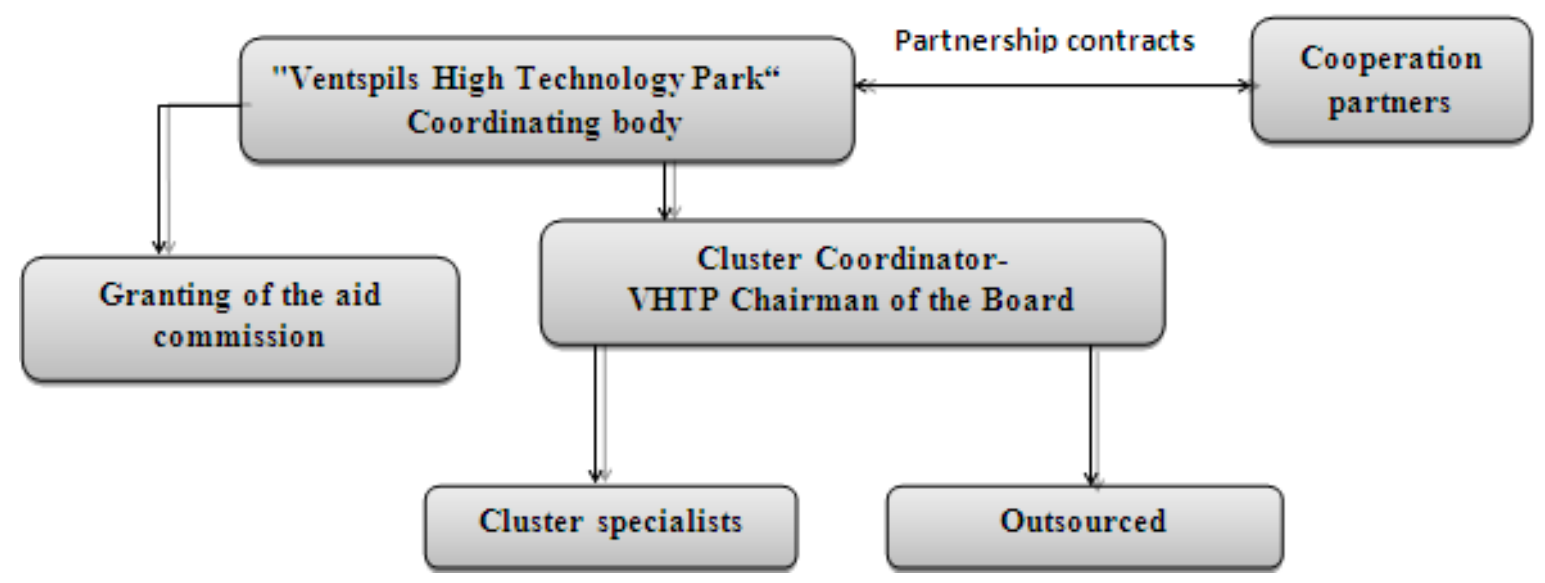

Figure 3. The organizational structure of the cluster (STC)

During the 4-year period, it can be seen that the turnover of members of the cluster is stable with a growing dynamics. Figure 2 shows the important role of small and medium-sized businesses in the total turnover of cluster members. At the same time, without support from the regional authorities and VHTP, the cluster would not be able to function. If we follow the organizational structure of a cluster, you can see the role played by VHTP.

The organizational structure of the cluster is shown in Figure 3.

Without going into details of the organizational structure, mention only the main directions of the cluster work Initiator of Space Technologies Cluster is Ventspils High Technology Park. Cluster Coordination body is connected to all parties by the Agreement of partnership. It coordinates the work of the cluster staff and external service providers, and, if necessary, involves experts. Cluster Coordinator VHTP provides separate accounting for the cluster related financial activities. Coordinator has some responsibility for the implementation of the activities, objectives and results, the timing and the movement of funds. The Commission is responsible for the distribution of cash assistance (support). The cluster manages the funds, of which cluster cooperation partners can get support de minimis. De minimis - support does not exceed EUR 200 000. Cluster specialists carry out administrative activities on the preparation of documents, interact with business partners in the planning and implementation of projects. They also carry out consulting for projects, conferences, international exhibitions.

All this has allowed developing a strategy, action plan and organizational model of Cluster of space technologies. Said document defines the goals, objectives and planned results Cluster on medium and long term.

In the last ten years, a number of clusters have been launched in Latvia, including the Life Science Cluster of Latvia (chemicals and pharmaceuticals), CLEANTECH Latvia (clean technologies in the industry), The Latvian Wood Construction Cluster and others. Some of them are co-financed by the European Fund regional development. Based on the analysis of the activity of Space Technology Cluster, and the information resulting from conversations and interviews from the above clusters SWOT analysis was made in relation to the Latvian clusters (Figure4).

Despite the presence of the clustering strengths, weaknesses, as well as the threats remain significant. Businessmen are ready for this process, but without the support of the state they cannot go on. Cluster policy in Latvia is poorly developed in comparison with the desired state and the best practices in Europe. Among the main reasons we can name the following.

Latvia is characterized by the absence of traditions of statehood, the poor quality of the political elite and, consequently, a heightened reaction to real and perceived security threats (language policy, the growth of military spending). Added to this is the lack of political will, strategic vision and responsibility.

Along with this, we can say about the exhaustion of the old model of economic development. Currently, the state system of human resource formation is neither meaningful nor in form, to develop people for life in the new reality. It lags far behind many EU countries in the field of entrepreneurship, intellectual assets, innovation and investment. 

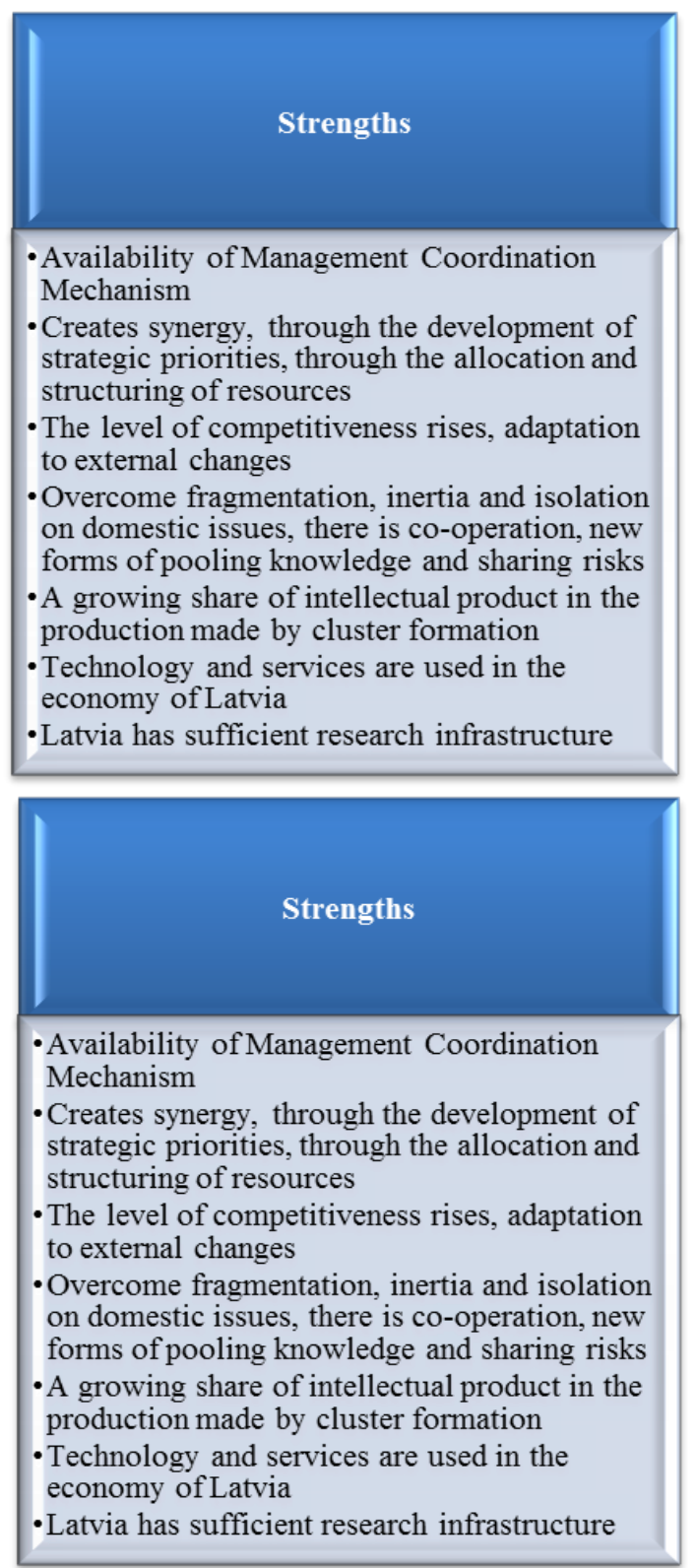
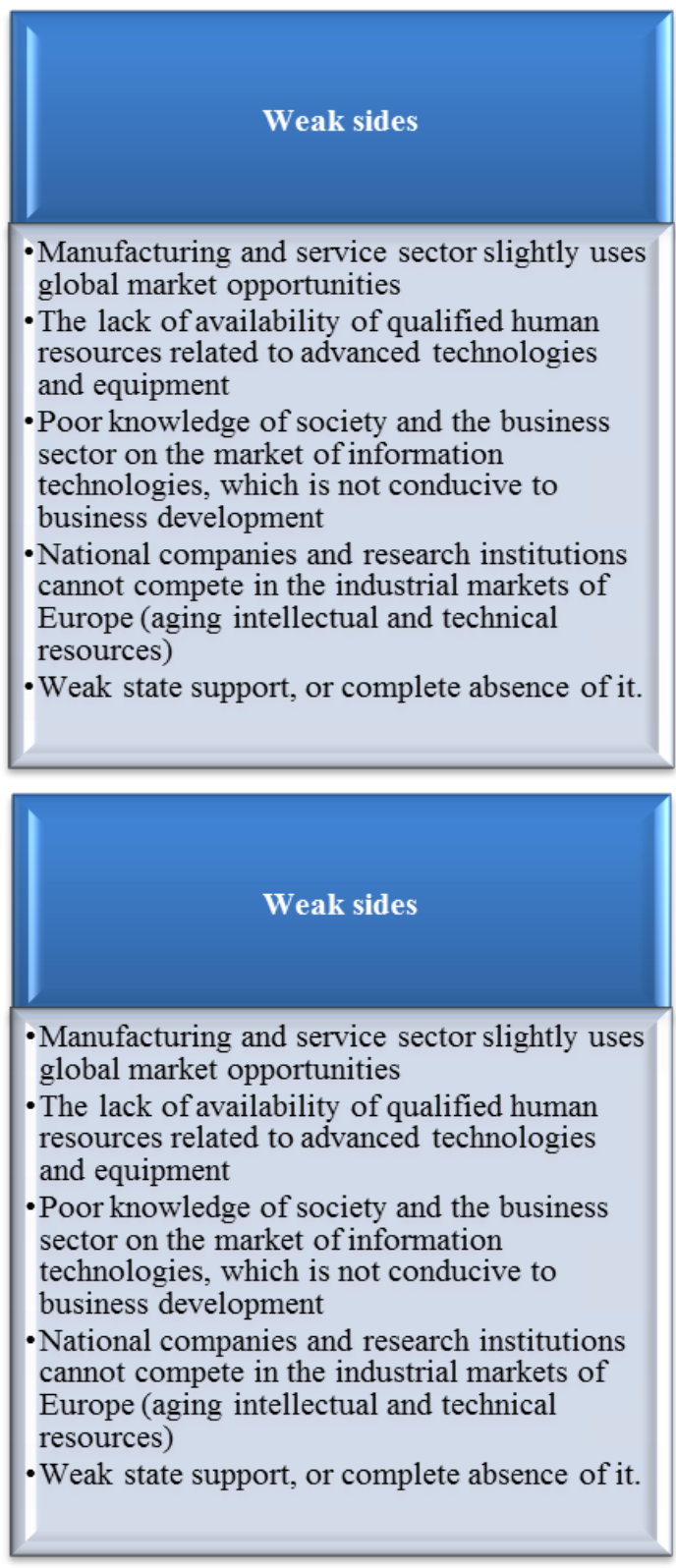

Figure 4. SWOT analysis in relation to the Latvian clusters.

Development of small and medium-sized businesses with subsequent clustering is important in terms of public policy. It makes the development of small clusters more efficient, provides technical assistance, helping with the concentration of firms.

In addition, to further the economic development of this approach is important because the clustering of small businesses will contribute to its survival and the development of other sectors of the local economy and will be the driver of Latvia.

Strong public policy, on the one hand, allows you to create a concept and a long-term strategy for the development of the innovation system, on the other hand - to implement specific measures to support and stimulate these stages of innovation processes, where only market incentives are not enough.

In the aspect of state power clusters represent a more "comfortable" object of control than many scattered producers of goods and services. The cluster initiatives and cluster strategies should not be viewed only through the prism of the expected economic results, but not least in the aspect of power and social responsibility.

In addition to that, factors that complicate doing business in Latvia, can be called an inefficient bureaucracy, excessive administrative powers, tax regulations, corruption and political instability.

We believe that the main problem in the development of small business in Latvia was and is the scarcity of funds allocated by the state. State guarantees, intended for its lending, are insufficient. The state should legally support the export of goods produced by small and medium-sized enterprises. Small businesses should be considered by the state as the main driver for innovation, employment and 
social integration in Europe.

This involves the implementation of a flexible government policies aimed at improving education, infrastructure and innovation, basic research, support for small and medium-sized businesses.

We need a new academic culture that will promote the development of innovation-cluster model of economic development. It requires from the state an awareness of the importance of this area, and its long-term support for basic research. Very important is the state policy in the field of education. This means training and retraining, the creation of oases of students. It is also necessary to develop a creative environment. This requires innovative teaching that enhances the entrepreneurial spirit, the development of venture businesses, increased abilities for the development of information technologies.

Finally, the government should at least not interfere with the business activity of entrepreneurs. It is required to create a stable legal framework for business and with the help of economic and administrative methods of management, to pursue an active policy of support for small and medium-sized businesses.

Today, many governments see the only way to save small businesses in the context of globalization and increasing international competition in combining them into clusters. After all clusters - this is a new way of thinking about the economy, and this involves learning new roles as entrepreneurs, and government to increase the competitiveness.

Latvia is, at whom to learn. So, The Ministry of Infrastructure and Environment of the Netherlands has commissioned a study on the involvement of micro-enterprises in INTERREG programmes (transnational strand). Finland is taking quite pragmatic approach to cluster innovations. It is made sure that the public and private sectors interact with each other and develop a joint strategy. The findings of this analysis will guide decision-makers of the North Sea Region and the North West Europe programmes when setting rules and procedures for the next period 2014-2020.

The cluster approach to economic management in Finland was used to develop the country's industrial policy, after which it became extremely popular. The peculiarity of the Finland is small economy that does not have self-sustained domestic demand. Due to the fact that the Finnish economy has no significant natural resources, the main engine of economic growth and clustering is a high level of innovation. Innovation is widely implemented thanks to development of the education sector, which is also a result of effective public policy.

Specialists of the Institute of the Finnish Economy Research (ETLA) offered 9 branches, which were carried out as the basis of the procedures associated with the formation of clusters. All clusters were divided into three groups (categories), "strong", "sustainable" and "potential". One of the strongest clusters became telecommunications products.

Exploring the history of formation, as well as the most important trends in the development of Finnish clusters, we can identify some of the characteristics. In all cases, the most important factor for modern competitiveness of clusters is a high level development of system-related institutions and industries. On the one hand, this was the result of market relations and effective competition, and in regard to the formation of the national innovation system and the training of qualified personnel, - the unconditional credit to public policy. This is the competent state policy to ensure the correct choice of promising market niches and investment priorities.

The revealed features of Finland, which has gone from being an outsider to the leading EU countries, allow to justify the need to use this experience for Latvia. First and foremost, Latvia should publicly proclaim and to develop a national innovation strategy for the next few years. As M. Porter noted for its formation and existence it is necessary the availability of long-term political and economic guaranties on the part of the state [15]. The invention of innovations and the generation of new knowledge should be recognized as a way of improving competitiveness of the country, therefore, namely, these two concepts should occupy a key place in the national strategy of Latvia.

\section{Summary and Concluding}

Improving the competitiveness of Latvia is possible only through the formation of a new economic development model - the clustering of the economy of small and medium-sized businesses. Cluster formation allows the national industry and the country as a whole, to maintain and develop their competitive advantage, and not to give it to those countries that are more likely to upgrade.

Enterprises from cluster thanks to mutual lapping become carriers of the same "business ideology" and play not only the role of the points of growth of the domestic market, but also bases entering the markets of other countries. Sectoral approach to the development of Latvia's economy, sooner or later, will be replaced by the cluster method.

The government gets many roles in this process. This means macroeconomic and political stability, the creation of rules and incentives governing competition, the development of long-term program of a competitive economy for the mobilization of public institutions, businesses and society. All this means creating a favorable environment for the cultivation of the first sprouts of a competitive innovative-cluster economy.

Development of small and medium business in Latvia should occur only in line with the priorities of EU innovation policy. But it should be adapted to the specific realities of the country, its national, historical and territorial characteristics, and adjust the dynamics of the changes to the fast-growing challenges. Therefore, further study is proposed to channel into the creation of innovation clusters of small forms and tracking processes that hinder cluster development in Latvia. 


\section{REFERENCES}

[1] Porter M. E. The Competitive Advantage of Nations. - New York: Free Press, 1990.

[2] Porter Michael E. Location, Competition, and Economic Development: Local Clusters in a Global Economy // Economic Development Quarterly. - 2000. - 14 (February).

[3] Porter M.E. The Economic Performance of Regions // Regional Studies. 2003. Vol. 37. № 6-7. P.549-678.

[4] Maskell Peter. Towards a Knowledge-Based Theory of the Geographic Cluster, Industrial and Corporate Change, 2001, 10 (December).

[5] Боуш Г.Д. Новый взгляд на онтологию кластеров предприятий//Экономическая наука современной России. - 2011. - №1.

[6] Ketels Ch. European Clusters. Structural Change in Europe. 3: Innovative City and Business Regions. Hagbarth Publications, 2004.

[7] Lundvall B., Johnson B. The Learning Economy // Journal of Industry Studies, Vol. 1, 1994.-pp. 23-42.

[8] Ketels, C. 2003,"Clusters of Innovation in Europe", in: Structural Change in Europe 3 -Innovative City and Business Regions, Bollschweil: Hagbarth Publications.

[9] Enright M., Regional Clusters, Economic Development: A Research Agenda, // Staber, U., Schaefer , N., Sharma, B., (Eds.) Business Network: Prospects for Regional Development, Berlin: Walter de Gruyter, 1996, pp. 190-213

[10] Малый и средний бизнес: чем может помочь EC. URL: http://rus.delfi.lv/news/daily/europe/malyj-i-srednij-biznes-c hem-mozhet-pomoch-es.d?id=30185385

[11] Латвийское центральное статистическое бюро. URL: http://www.ur.gov.lv/statistika.html?a=1080

[12] Латвийское агентство инвестиций и развития. URL: http://www.liaa.gov.lv/ru/investitsii-v-latvii/biznes-putevodit el-latvii/pryamye-inostrannye-investitsii

[13] Porter, M. E. (1998) On Competition. Boston: Harvard Business School Press.

[14] Space Technology Cluster URL: http://www.vatp.lv/en/Space ClusterThe findings of this analysis will guide decision-makers of the North Sea Region and the North West Europe programmes when setting rules and procedures for the next period 2014-2020.Porter M., Stern S. Innovation: Location Matters // Sloan Management Review. 2001. Summer. P. 28-36 